\title{
Barriers and perceived limitations to early treatment of hemophilia
}

\author{
This article was published in the following Dove Press journal: \\ Journal of Blood Medicine \\ 15 May 2013 \\ Number of times this article has been viewed
}

\author{
Kapil Saxena \\ Boston Hemophilia Center, Boston \\ Children's Hospital, Boston, MA, USA
}

\begin{abstract}
Early treatment of bleeds in hemophilia patients, both with and without inhibitors, has been shown to be of immense benefit in the overall clinical outcome. Despite the advantages of treating the bleeding episodes early, significant barriers and limitations remain. The aim of this review is to highlight the various barriers and perceived limitations to early therapy of bleeding episodes, especially in patients who have developed inhibitors to factor VIII. The peer-reviewed literature was searched for articles on hemophilia patients, with and without inhibitors, and early treatment, to identify the barriers to early treatment and potential impact on patient outcomes. The most important barrier is the educational barrier, which involves lack of awareness among patients regarding the signs of a bleed, as well as importance of early therapy. It is also common for parents or caregivers of school-age children to exhibit inconvenience and scheduling barriers. Distance to the treatment center can also play a role here. Some patients experience financial barriers related to cost of clotting factor products, insurance coverage, or insurance caps and out-of-pocket costs. Rarely, there can also be problems related to venous access or home infusion. Lastly, multiple psychosocial barriers can prevent adherence to treatment regimens. Identification and addressing these individual barriers will result in improved compliance rates, prevent joint damage, be more cost-effective, and lead to better overall health of these patients.
\end{abstract}

Keywords: hemophilia A, hemophilia B, inhibitors, outcomes, quality of life, cost of care

\section{Introduction}

Hemophilia is a rare, inherited, X-chromosome-linked bleeding disorder resulting from a deficiency of clotting factor VIII (hemophilia A) or factor IX (hemophilia B). Inhibitors to clotting factors VIII and IX develop in $20 \%-33 \%$ of patients with moderate to severe hemophilia A and in 1\%-6\% of patients with hemophilia B. Treatment options are typically more limited for hemophilic patients with inhibitors compared to those without inhibitors. In addition, a majority of hemophilic patients live in the developing world, where there is little or no access to factor-replacement therapy, leading to greater mortality and morbidity in the developing world. ${ }^{1}$ In these less developed nations, the greatest challenges include recognition and diagnosis of hemophilic patients, and the lack of trained health-care professionals with the knowledge to prescribe factor products properly and safely. ${ }^{1}$

Initiation of primary prophylaxis, with infusions of factor VIII before or soon after the first bleeding episode, has been shown to reduce joint bleeding and osteochondral changes, and leads to better musculoskeletal outcomes in patients without inhibitors. ${ }^{2,3}$ Several studies ${ }^{4-6}$ have reported on the benefits of early treatment with bypass agents for bleeds in hemophilic patients with inhibitors (Table 1). The efficacy of early
Correspondence: Kapil Saxena Boston Hemophilia Center, Children's Hospital Boston, 300 Longwood Avenue Fegan 707, Boston, MA 02115, USA

$\mathrm{Tel}+\mathrm{I} 6173550956$

Fax + | $617730064 \mid$

Email kapil.saxena@childrens.harvard.edu 
Table I Benefits of early treatment of hemophilic patients with inhibitors

I. Earlier resolution of, and more rapid recovery from, bleeding episodes $^{6}$

2. Improved efficacy at lower dose and lower $\operatorname{cost}^{4-6}$

3. Reductions in long-term arthropathy ${ }^{6}$

4. Reductions in hospitalizations and surgeries required ${ }^{6}$

5. Possibility of home treatment ${ }^{4}$

treatment of intramuscular hemorrhage with the bypass agent recombinant activated factor VII (rFVIIa [NovoSeven]; Novo Nordisk, Bagsværd, Denmark) was compared using outcomes of three open-label studies 5 : a US home treatment study, ${ }^{4}$ a dose-escalation study, ${ }^{7}$ and a compassionate use study. ${ }^{8}$ The majority of patients had hemophilia A or B with high-titer inhibitors (a few in the compassionate use study had acquired hemophilia). The time interval from onset of bleeding to rFVIIa administration, the doses and number of injections required to achieve hemostasis, and global response to treatment were recorded for each bleeding episode. ${ }^{5}$ Patients in the home treatment study rapidly administered $90 \mathrm{mcg} / \mathrm{kg} \mathrm{rFVIIa}$ (mean time to treatment, 1.1 hours), with a $92 \%$ efficacy after a mean number of 2.2 injections. ${ }^{4}$ By contrast, patients in the dose-escalation study were treated at the hemophilia treatment center (HTC; median time to treatment, 10 hours), with a $72 \%$ efficacy after a mean number of 3.6 injections for the high-dose $(70 \mathrm{mcg} / \mathrm{kg})$ group. ${ }^{8}$ In the compassionate use study, where patients were treated late in the course of the bleed (mean time to treatment, 5 days) after other forms of treatment failed, the efficacy was $62 \%$ after a mean number of 13.6 doses (mainly at $90 \mathrm{mcg} / \mathrm{kg}$ [range 60 to $120 \mathrm{mcg} / \mathrm{kg}])^{7}$

The HemoRec registry in the Czech Republic recorded demographic information along with information regarding primary diagnosis, symptoms, treatments, and adverse events. ${ }^{9}$ Overall, $60.2 \%$ (77/128) of rFVIIa-treated bleeds were treated within 2 hours of bleed onset. Early treatment ( $\leq 2$ hours) with rFVIIa resulted in significantly fewer incidences of rebleeding than bleeds treated more than 2 hours after bleed onset. ${ }^{9}$ Despite the advantages of treating bleeding episodes early, significant barriers and perceived limitations remain for patients with hemophilia in seeking early treatment.

\section{Barriers and perceived limitations to early treatment Educational barriers}

Patients with hemophilia are not always knowledgeable about their disorder or how significantly their personal involvement in treatment can affect outcomes. Moreover, $30 \%$ of patients may have no familial history of hemophilia. Thus, long-term sequelae resulting from untreated bleeds are unknown to them and their families.

Lack of awareness concerning the importance of early treatment of bleeding episodes is a common barrier. Current World Federation of Hemophilia guidelines recommend the treatment of an acute bleed within 2 hours of its initiation. ${ }^{10}$ Young children are typically afraid of receiving injections. School-age children may also hide their bleeds for fear of being reprimanded or causing undue stress and financial liability to their family. ${ }^{11}$ Parents, in turn, may not wish to infuse an uncooperative child with clotting factor until they deem it absolutely necessary. Parents have reported feeling uneasy about injecting their child, a lack of confidence in their ability to carry out the injection correctly, and fear of causing harm or pain to their child as major challenges in home-based care. ${ }^{12}$ In regard to greater responsibility, parents reported difficulty in deciding the right form of treatment for their child, anxiety about contamination of blood products (often due to familial history), fear of the potential longterm side effects of prophylaxis, and a desire to avoid any unnecessary medications. ${ }^{12}$

Lack of awareness of the early signs of bleeding is a serious deficiency related to the lack of patient education. In response to a questionnaire survey distributed between 2008 and 2009, 47 physicians from Europe, the US, Africa, Australia, and Central and South America reported that although they recommend bleeds be treated within 1 hour of onset, in practice only $64.6 \%$ of bleeds were treated within $1-2$ hours. ${ }^{13}$ In a survey sponsored by the Centers for Disease Control and Prevention (CDC), only $31 \%$ of patients with hemophilia aged 13-21 years treated bleeding episodes within 1 hour, and 15\% waited over 6 hours. ${ }^{14}$ When patients were queried, $29 \%$ replied that they did not recognize the bleeding episode, and $11 \%$ did not think the bleed was serious enough to warrant treatment. Similarly, a global survey of practice patterns in the management of hemophilia A (2003 Practice Patterns Survey [PPS]) cited "infrequency of bleeding" as the primary reason that respondents ( $80 \%$ of patients and $60 \%$ of nurses) chose not to administer prophylactic treatment. ${ }^{15}$ Although early treatment of muscle hematomas is critical, difficulty in recognizing whether symptoms are due to a bleed or other muscle conditions (ie, contusions, strains) may delay treatment. ${ }^{16}$ Patients and their families should be mindful of bleeding symptoms and seek immediate medical attention when they appear. ${ }^{10}$

Instructional aids and programs dedicated to patients with hemophilia are invaluable, ${ }^{17}$ with the goal of empowering 
patients to take responsibility for their own treatment (Table 2). Patients should understand the particulars of their diagnosis and carry information indicating the type and severity of their condition, inhibitor status, type of clotting agent used, and contact information of the treating physician. ${ }^{10}$

Parents of minors with hemophilia have additional responsibilities. Extra care should be taken in childproofing the surroundings, although experts warn against overcompensation and overprotection. Parents should be extra-vigilant concerning changes in the child's actions and demeanor, such as an unusual gait, which may be symptomatic of a bleed. At the proper stage of the child's development, parents should gradually transfer responsibility for home infusion to the child to enhance independence and self-confidence. Today, many school-age children are technologically savvy and can easily use electronic patient diaries and computerized datamanagement tools to track bleeds and infusions, which may also increase treatment adherence. ${ }^{18,19}$

\section{Inconvenience and scheduling barriers}

Lack of time and inconvenience have been cited in surveys as primary barriers for both prophylaxis and early episodic treatment. ${ }^{20,21}$ Many parents and school-age children find it challenging to incorporate a prophylactic regimen into a busy morning schedule. The storage and administration of clotting agents also present significant barriers to early treatment. In the aforementioned CDC-sponsored survey, 25\% of patients who were not "early treaters" reported that they did not have clotting agent in their possession at the time of the bleed. ${ }^{14}$ Need for refrigeration is a further inconvenience and expense for patients, particularly those on prophylactic treatment, who must carry the clotting agents in a cooler during extended stays away from home. Moreover, administration of a single dose of clotting factor may be as brief as 2-5 minutes for some formulations or greater than 50 minutes for others. Finally, most clotting agents are not stable enough for room-temperature storage and require refrigeration, and

Table 2 Instructional aids and programs to help address educational needs

- Educational and instructional CDs and DVDs ${ }^{63}$

- More interactive video games, such as Nintendo Wii, ${ }^{64}$ which allow moderate amounts of physical activity

o Children with hemophilia who are restricted from playing contact sports often spend much free time playing video games in lieu of participating in physical activities outdoors s,65,66 $^{67}$

- Summer camps for children with hemophilia ${ }^{67}$

- Peer and mentor counseling services, where adults with hemophilia can mentor young children on coping with their condition over time must be reconstituted at room temperature immediately before use, resulting in further treatment delays.

Distance to an HTC remains a difficult barrier to overcome, particularly for patients who live in rural areas, those with no means of transportation, and those with crippling physical disabilities. In the Hemophilia Utilization Group Study part Va (HUGS-Va) that examined the cost and burden of illness in people with hemophilia in the US, three of the most frequently cited barriers for patients in seeking treatment at an HTC were "distance to the center" (30.0\%-43.8\%), "clinic hours were not convenient" (26.7\%-37.5\%), and "transportation to center" $(20.0 \%-31.3 \%){ }^{22}$ In the HUGS-Va study, the average distance from home to the HTC was $45.2 \pm 63.6$ miles $(72.7 \pm 102.4 \mathrm{~km})$. Additional options to encourage HTC utilization are listed in Table 3.

\section{Financial barriers}

An estimated $30 \%$ of patients with hemophilia in the US are uninsured or underinsured. ${ }^{23}$ Many private insurance companies have existing lifetime caps on coverage, which patients often quickly surpass. ${ }^{23}$ Consequently, patients may incur significant out-of-pocket costs, and thus in some instances forgo necessary treatment. ${ }^{23}$ In the aforementioned HUGS-Va study, $28.3 \%$ of patients reported that the primary barrier to their seeking care in an HTC was "insurance does not pay for comprehensive care at HTCs." 22 Recently, there has been a rise in the amount of copayments for families for the clinic visits and factor prescriptions.

\section{Hemophilic patients without inhibitors}

The annual cost of episodic treatment of an adult with mildto-moderate hemophilia (without comorbid conditions or arthropathy) in the US is estimated at $\$ 18,980 .{ }^{24}$ For patients with severe hemophilia and hemarthroses, the annual treatment cost may increase to $\$ 60,000-\$ 200,000 .^{24,25}$

Table 3 Options to encourage home infusion and hemophilia treatment center (HTC) utilization

\footnotetext{
Home

- Involve children in the treatment plan from an early age so that they can assist their busy parents and begin to take responsibility for managing their own condition

HTC

- Greater attention to maintain contact with patient during transition periods, especially adolescent-to-adult phase

- Develop regional adult clinics in cooperation with local hospitals

- Reimburse patients for transportation costs

- Encourage HTC hematologists to travel to hospitals within the state to present seminars and grand rounds to educate local medical personnel on hemophilia management
} 
A retrospective study of US health insurance claims between 2002 and 2008 in patients with hemophilia with employersponsored insurance showed mean annual cost was higher for patients with hemophilia A than those with hemophilia B (\$162,054 versus $\$ 127,194, P=0.06) .{ }^{26}$ In patients with Medicaid, the mean annual cost for patients with hemophilia A was $\$ 148,215$ and $\$ 113,223$ for those with hemophilia B. ${ }^{27}$ Annual costs were similar for children and adults, overall.

\section{Hemophilic patients with inhibitors}

The cost of treating patients with inhibitors relative to patients without inhibitors varies widely in the literature, from a 1.3-fold to a tenfold higher cost, including increased clotting agent use, hospitalization, and surgery. ${ }^{25,28,29}$ The cost of care in these patients is typically more than $\$ 100,000$ annually, excluding the cost of elective orthopedic surgery and immune-tolerance therapy (ITT). In the aforementioned retrospective claims study, for patients with inhibitors with employer-sponsored insurance, mean annual cost of treatment was 4.8 times higher compared to those without inhibitors $(\$ 696,279, P<0.01),{ }^{26}$ and for those with Medicaid, mean annual cost was 3.6 times higher $(\$ 446,945, P<0.01) .{ }^{27}$

\section{Comorbid conditions}

Comorbid conditions, such as obesity, synovitis, liver disease, HIV infection, and hepatitis $\mathrm{C}$ virus (HCV) infection, add substantial direct and indirect costs to the treatment of patients with hemophilia. A retrospective claims analysis of the PharMetrics database over a 7-year period determined that treatment of hemophilic patients without inhibitors coinfected with HIV and HCV was 59\% more costly than treatment of uninfected hemophilic patients without inhibitors (\$144,462 versus $\$ 90,942$, respectively). ${ }^{30}$ The HUGS study reported that HIV seropositivity, along with arthropathy and the presence of inhibitors, is most significantly $(P<0.05)$ correlated with higher health-care costs and greater factor VIII consumption. ${ }^{31}$ In the previously mentioned retrospective claims study, patients with employer-sponsored insurance infected with HIV or HCV had mean annual costs 1.5 times higher than uninfected patients $(\$ 125,861, P<0.01) .{ }^{26} \mathrm{In}$ the PharMetrics claims analysis, mean factor VIII costs were $45 \%$ higher for $\mathrm{HIV} / \mathrm{HCV}$-coinfected hemophilic patients without inhibitors $(\$ 113,228)$ than for uninfected hemophilic patients without inhibitors $(\$ 77,863) .{ }^{30}$ This increased cost was particularly evident during end-stage AIDS, when factor VIII usage may increase by more than $50 \%$ from prior levels. ${ }^{32}$

\section{Prophylaxis}

In the US, approximately one-half of children with severe hemophilia A and one-third of those with severe hemophilia B are on prophylaxis, although there is considerable regional variability. ${ }^{33}$ The estimated annual cost ranges from $\$ 300,000$ to $\$ 440,000,{ }^{24,34}$ but varies depending on disease severity and inhibitor status.

Despite the demonstrated clinical benefits of prophylaxis in early childhood, ${ }^{34-36}$ compliance is markedly lower for patients on high-intensity treatment regimens, such as prophylaxis compared with episodic treatment. ${ }^{37}$ In the 2003 PPS, "high cost" was the third most frequently cited reason that respondents (45\%) chose not to administer prophylaxis. ${ }^{15}$

Despite the high cost, the use of prophylactic agents may ultimately be cost-saving, especially when compared with the combined use of ITT and episodically administered clotting agents in hemophilic patients with inhibitors. ${ }^{38}$ One study estimated savings of $\$ 8,312-\$ 17,675$ per bleeding episode in a patient with severe hemophilia without inhibitors. ${ }^{39}$ Additional adjustments in dosing and frequency of administration have resulted in savings of more than $\$ 58,000$ per patient with severe hemophilia. ${ }^{40}$

\section{Immune tolerance therapy}

ITT is the primary treatment used to eliminate inhibitors in hemophilic patients. The average cost of ITT may approach or even exceed \$1 million in patients with good prognostic indicators (ie, pre-ITT titers less than 10 Bethesda units and less than 5 years since inhibitor diagnosis), but can be fivefold higher in patients with poor prognostic indicators. ${ }^{41}$

\section{Elective orthopedic surgery}

The most common sequela following a lifetime of bleeding episodes, especially in patients with inhibitors, is severe arthropathy. Use of walking aids and wheelchairs was more than $20 \%$ higher in patients with severe hemophilia and inhibitors aged $14-35$ years ( $50 \%$ and $24 \%$, respectively) compared to those without inhibitors ( $29 \%$ and $4 \%$, respectively). ${ }^{42}$

The costs of any given orthopedic procedure are related to the duration of hospitalization and replacement clotting factor consumption; for example, surgical synovectomy $(\$ 61,000)$ is far more costly than outpatient radiosynovectomy $(\$ 2,850) .{ }^{43}$ The average knee surgery in hemophilic patients with inhibitors, including perioperative rFVIIa coverage, costs between $\$ 694,000$ for knee arthrodesis to $\$ 855,000$ for total knee replacement, with proximal tibial osteotomy and distal femoral osteotomy intermediate in cost. ${ }^{44}$ Consistent with these studies, the cost of elective orthopedic surgery for patients with inhibitors (range \$5000-\$500,000) can be 
as much as ten times more than for those without inhibitors (range \$5000-\$50,000). ${ }^{45}$

\section{Quality of life}

Quality of life (QoL) assessment tools are being used with increasing regularity in both clinical trials and pharmacoeconomic modeling studies to unravel the potential long-term benefits of expensive procedures, such as prophylaxis, ITT, and elective orthopedic surgery. The high cost of prophylactic therapy, for example, is weighed against improvements in QoL, days gained at work and school, reduced hospitalizations, and reduced need for surgery. ${ }^{46-48}$ The European Haemophilia Economic Study Group compared the outcomes of 1033 hemophilic patients from 16 European HTCs using prophylaxis with episodic treatment. ${ }^{49}$ The patients on prophylactic therapy reported less pain and improved health, and performed better on three of the eight measured QoL indices (mental health and physical and social functioning). In a Dutch study of 49 patients with severe hemophilia, the cohort on prophylaxis had fewer joint bleeds per year (median 2.8 versus 11.5 ), improved clinical scores (median 2.0 versus 8.0 ), and less arthropathy (median 7 points versus 16 points by Pettersson scoring) than the cohort being treated episodically, but with comparable clotting factor usage. ${ }^{36}$

A modeling analysis using a standard ITT regimen (ie, $100 \mathrm{IU} / \mathrm{kg} /$ day of FVIII for 420 days) for a prototypical 5 -year-old boy with severe hemophilia and high-titer inhibitors was projected to increase his life expectancy by 4.6 years and result in a lifetime reduction in the cost of clotting agent of $\$ 1.7$ million. ${ }^{41}$ Knee surgery is expected to reduce mean annual bleeding episodes at the target joint from 9.13 to 1.64 (based on efficacy studies), such that the cost of elective orthopedic surgery is offset at 8-10 years after surgery. ${ }^{44}$ Another analysis predicted that total hip replacement in a $75 \mathrm{~kg}$ patient experiencing one bleed per month in the target joint could result in net savings of $\$ 448,000$ over 5 years when a reduction in future bleeds was considered. ${ }^{50}$

In general, findings from these studies support QoL benefits for positive outcomes in hemophilic patients undergoing prophylaxis, ITT, and elective orthopedic surgery. Patients with limited financial means should seek state, federal, and corporate financial support ${ }^{51,52}$ to take full advantage of these high-intensity, costly treatments (Table 4).

\section{Technical barriers}

The self-management of bleeds via home infusion of clotting agent requires significant commitment by patients and experienced health-care practitioners. ${ }^{53}$ Issues include
Table 4 Opportunities to help overcome financial barriers

- Access to free health-care clinics sponsored by the US Department of Health and Human Services

- High-risk insurance pools, state children's health insurance programs, and support programs

- Assistance in navigating insurance plans from reimbursement specialists at hemophilia treatment centers and the National Hemophilia Foundation

- Emergency financial aid from some hemophilia treatment centers

finding a vein, using a nondominant hand, and dealing with fear of needles. In the 2003 PPS, difficulties with venous access was the second most frequently (60\%) cited reason for respondents who chose not to administer prophylactic treatment. $^{15}$

Insertion of a central venous access device alleviates many of the problems associated with home infusion of clotting agent, and is convenient for both medical personnel and patients who self-inject. A Dutch study demonstrated that hemophilic patients with a central venous access device begin prophylaxis and home treatment at an earlier age. ${ }^{54}$ Significant drawbacks to the use of many of these types of devices are increased risks of infections and thrombotic complications. ${ }^{54,55}$ Technical complications may also occur, such as a catheter that is blocked, damaged, buckled, poorly positioned, or disconnected from the port or skin erosion over the port. ${ }^{55,56}$ Suggestions to minimize infections and other complications $^{10,55}$ are provided in Table 5 .

\section{Psychosocial barriers}

With the recent interest in psychometric assessments of the well-being of patients with hemophilia, the psychological and social barriers to patient and parental compliance with treatment have been examined. These include denial;

Table 5 Solutions to help overcome technical barriers

- Training of patients and their parents in the proper management of prophylactic or home infusion regimens including:

- Bleed recognition

- Dosage calculation

- Preparation, storage, and administration of clotting factor

- Aseptic technique

- Performing venipuncture or accessing the central venous access device

- Record-keeping (to track bleeding episodes and infusion schedules)

- Biohazard cleanup (including needles and spills) ${ }^{10,55}$

- Patients or their parents must be trained on the proper maintenance of venous access lines to avoid infections

- Follow-up and repeated education on proper system operation

- Patients should clean the injection site with soap and water before administration 
fear of pain, hospitals, and needles; the parental burden of providing care along with a balance of caution and control for the child; risky behavior in teenagers; and the adolescentto-adult transition. In some countries, viral transmission of HCV and HIV through the national blood supply has left a legacy of fear and distrust between patients and the health authorities. ${ }^{15,57}$ Parents may have a difficult time adjusting to

Table 6 Options to help overcome psychosocial barriers

Infants and toddlers

I. Coming to terms with the diagnosis of hemophilia as soon as possible

2. Developing coping strategies for their new reality because hemophilia is a lifelong, chronic condition

3. Developing lasting relationships with a hemophilia care team

4. Finding the right hemophilia support groups

5. Distinguishing between caution and overprotection, and guiding the child's confidence in daily activities

School-age children

I. Educating the child on the basics of hemophilia at his level of comprehension

2. Stressing to the child how important it is to treat a bleed, and that he will neither get into trouble for disclosing a bleed nor be kept from his favorite risk-appropriate activity once the bleeding has stopped

3. Facilitating discussions with school officials concerning the child's condition, the future likelihood of missed school days, the school nurse's ability to safely inject replacement clotting factor during a bleeding episode, and systems in place in case of an emergency

4. Creating occasions for social interactions with family and friends to promote the child's positive social development

5. Sharing any psychological and emotional strains that the condition is having on the parents and siblings, and referring them to counselors and/or support groups

Preadolescent and adolescent children

I. Encouraging the child to actively participate in the management of their bleeds at preadolescence, leading to more autonomy and selfmanagement at adolescence

2. Encouraging the child to avoid unnecessary risks, and setting boundaries without becoming overprotective

3. Familiarizing the child with an infusion of clotting factor in the morning of any day when extra exertion will be required (eg, sporting events or field trips), whether or not they are on a prophylactic regimen ${ }^{10,21,61}$

4. Helping the child deal with physical changes and health issues common to this age-group

5. Guiding the child through psychosocial issues such as self-esteem and social peer interactions

Adolescent-to-adult transition

I. Ensuring that the young adult with hemophilia who moves out of his parents' home transitions to a new health-care provider or hemophilia treatment center, if necessary

2. Encouraging continued compliance with early treatment or prophylaxis to avoid any worsening orthopedic condition

3. Guiding the young adult to a smooth and safe transition into the workforce

4. Encouraging continued social interaction or hemophilia support groups the child's diagnosis. In multiple surveys, "denial" and "lack of parental/family commitment" consistently ranked among the most frequent responses to why patients do not adhere to treatment regimens. ${ }^{15}$

Every stage in a child's development is characterized by unique life challenges that have a dramatic impact on treatment for hemophilia. The time at which a child begins school coincides with increased socialization and cognitive development. They may begin to take excessive risks to fit in with their peers and hide their bleeds, with potentially serious consequences. ${ }^{11}$ Adolescents have a reduced compliance with prophylaxis compared with younger age-groups. ${ }^{15,58}$ Even in Scandinavia, where patients with hemophilia are highly compliant, $41 \%$ of patients aged 13-25 years were noncompliant at some point during the prescribed prophylactic regimen. ${ }^{21}$ Reduced compliance with early and preventive treatment in adolescence is especially disconcerting, because learning to self-infuse is a big step toward independence and self-confidence for a patient with hemophilia.

Adults with hemophilia whose bleeds were aggressively treated when living in their parents' home then become responsible for their own treatment. Some adult patients who had stable joints while under prophylaxis from childhood, later neglect treatment, and physicians may be treating patients with worsening arthropathy as a result. ${ }^{59,60}$ Suggestions to minimize psychosocial barriers in patients with hemophilia ${ }^{10,21,61}$ are provided in Table 6.

\section{Conclusion}

Two of the most critical yet tractable parameters affecting the degree of arthropathy in patients with hemophilia are physical activity and the timing of treatment. Early treatment of bleeding episodes in hemophilic patients both with and without inhibitors:

1. likely delays arthropathic progression and disability ${ }^{2,62}$

2. improves efficacy at stopping bleeds ${ }^{5,9}$

3. results in the use of less product and is more costeffective $^{5}$

4. delays or prevents the need for more expensive interventions later. ${ }^{5,6}$

Understanding what prevents patients with hemophilia from seeking early treatment and determining their attitudes and preferences with respect to treatment may lead to improved compliance rates and better overall health for these patients.

Barriers and perceived limitations to early treatment in patients with hemophilia can be broadly classified 
as educational barriers, inconvenience and scheduling barriers, financial barriers, and psychosocial barriers. While hematologists have often focused on the treatment regimens of patients with hemophilia, health-care providers need to address nontreatment concerns that affect patient compliance, particularly in the psychosocial arena.

\section{Acknowledgments}

Editorial assistance was provided by Amanda Tricarico, $\mathrm{PhD}$, ETHOS Health Communications, Newtown, PA, USA, with financial assistance from Novo Nordisk, in compliance with international guidelines for good publication practice.

\section{Disclosure}

Dr Saxena has received research support from and has participated in advisory boards for Novo Nordisk. He has received no remuneration of any kind for the development of this manuscript.

\section{References}

1. Young G. New challenges in hemophilia: long-term outcomes and complications. Hematology Am Soc Hematol Educ Program. 2012;2012:362-368.

2. Fischer K, van der Bom JG, Mauser-Bunschoten EP, et al. The effects of postponing prophylactic treatment on long-term outcome in patients with severe hemophilia. Blood. 2002;99(7):2337-2341.

3. Dunn AL. Pathophysiology, diagnosis and prevention of arthropathy in patients with haemophilia. Haemophilia. 2011;17(4):571-578.

4. Key NS, Aledort LM, Beardsley D, et al. Home treatment of mild to moderate bleeding episodes using recombinant factor VIIa (Novoseven) in haemophiliacs with inhibitors. Thromb Haemost. 1998;80(6):912-918.

5. Lusher JM. Early treatment with recombinant factor VIIa results in greater efficacy with less product. Eur J Haematol Suppl. 1998;63: $7-10$.

6. Munro V. The cost effectiveness of a new formulation of recombinant factor VIIa in the home treatment of mild to moderate bleeding episodes in haemophilia A patients with inhibitors in the United Kingdom. 50th American Society of Hemophilia Annual Meeting and Exposition; December 6-9, 2008; San Francisco, CA, USA.

7. Lusher JM, Roberts HR, Davignon G, et al. A randomized, double-blind comparison of two dosage levels of recombinant factor VIIa in the treatment of joint, muscle and mucocutaneous haemorrhages in persons with haemophilia A and B, with and without inhibitors. rFVIIa Study Group. Haemophilia. 1998;4(6):790-798.

8. Lusher JM. Recombinant activated factor VII for treatment of intramuscular haemorrhages: a comparison of early versus late treatment. Blood Coagul Fibrinolysis. 1998;9 Suppl 1:S111-S114.

9. Salaj P, Brabec P, Penka M, et al. Effect of rFVIIa dose and time to treatment on patients with haemophilia and inhibitors: analysis of HemoRec registry data from the Czech Republic. Haemophilia. 2009; 15(3):752-759.

10. Srivastava A, Brewer AK, Mauser-Bunschoten EP, et al. Guidelines for the management of hemophilia. Haemophilia. 2013;19(1):e1-e47.

11. Cassis F. Psychosocial Care for People with Hemophilia. Quebec: World Federation of Hemophilia; 2007.

12. Shaw D, Riley GA. The impact on parents of developments in the care of children with bleeding disorders. Haemophilia. 2008;14(1): $65-67$.
13. Sorensen B, Dargaud Y, Kenet G, et al. On-demand treatment of bleeds in haemophilia patients with inhibitors: strategies for securing and maintaining predictable efficacy with recombinant activated factor VII. Haemophilia. 2012;18(2):255-262.

14. Nazzaro AM, Owens S, Hoots WK, Larson KL. Knowledge, attitudes, and behaviors of youths in the US hemophilia population: results of a national survey. Am J Public Health. 2006;96(9):1618-1622.

15. Geraghty S, Dunkley T, Harrington C, Lindvall K, Maahs J, Sek J. Practice patterns in haemophilia A therapy: global progress towards optimal care. Haemophilia. 2006;12(1):75-81.

16. Salek SZ, Benson GM, Elezović I, et al. The need for speed in the management of haemophilia patients with inhibitors. Haemophilia. 2011;17(1):95-102.

17. Stettler N, Signer TM, Suter PM. Electronic games and environmental factors associated with childhood obesity in Switzerland. Obes Res. 2004;12(6):896-903.

18. Mondorf W, Siegmund B, Mahnel R, et al. Haemoassist - a hand-held electronic patient diary for haemophilia home care. Haemophilia. 2009; 15(2):464-472.

19. Arnold E, Heddle N, Lane S, Sek J, Almonte T, Walker I. Handheld computers and paper diaries for documenting the use of factor concentrates used in haemophilia home therapy: a qualitative study. Haemophilia. 2005;11(3):216-226.

20. Hacker MR, Geraghty S, Manco-Johnson M. Barriers to compliance with prophylaxis therapy in haemophilia. Haemophilia. 2001; 7(4):392-396.

21. Lindvall K, Colstrup L, Wollter IM, et al. Compliance with treatment and understanding of own disease in patients with severe and moderate haemophilia. Haemophilia. 2006;12(1):47-51.

22. Zhou ZY, Riske B, Forsberg AD, et al. Self-reported barriers to hemophilia care in people with factor VIII deficiency. Am J Prev Med. 2011; 41(6 Suppl 4):S346-S353.

23. Iowa Hemophilia Advisory Committee. Report to the governor and general assembly. 2009. Available from: http://www.idph.state.ia.us/ adper/common/pdf/legis/2009_hemophilia.pdf. Accessed April 4, 2013.

24. Globe DR, Curtis RG, Koerper MA. Utilization of care in haemophilia: a resource-based method for cost analysis from the Haemophilia Utilization Group Study (HUGS). The HUGS Steering Committee. Haemophilia. 2004;10 Suppl 1:63-70.

25. Ullman M, Hoots WK. Assessing the costs for clinical care of patients with high-responding factor VIII and IX inhibitors. Haemophilia. 2006;12 Suppl 6:74-79; discussion 79-80.

26. Guh S, Grosse SD, McAlister S, Kessler CM, Soucie JM. Healthcare expenditures for males with haemophilia and employer-sponsored insurance in the United States, 2008. Haemophilia. 2012;18(2):268-275.

27. Guh S, Grosse SD, McAlister S, Kessler CM, Soucie JM. Health care expenditures for Medicaid-covered males with haemophilia in the United States, 2008. Haemophilia. 2012;18(2):276-283.

28. Goudemand J. Treatment of patients with inhibitors: cost issues. Haemophilia. 1999;5(6):397-401.

29. Teitel J. Inhibitor economics. Semin Hematol. 2006;42 Suppl 4: S14-S17.

30. Tencer T, Friedman HS, Li-McLeod J, Johnson K. Medical costs and resource utilization for hemophilia patients with and without HIV or HCV infection. J Manag Care Pharm. 2007;13(9):790-798.

31. Globe DR, Cunningham WE, Andersen R, et al. The Hemophilia Utilization Group Study (HUGS): determinants of costs of care in persons with haemophilia A. Haemophilia. 2003;9(3):325-331.

32. Kennelly JM, Tolley KH, Ghani ACH, Sabin CA, Maynard AK, Lee CA. Hospital costs of treating haemophilic patients infected with HIV. AIDS. 1995;9(7):787-793.

33. Manco-Johnson MJ. Update on treatment regimens: prophylaxis versus on-demand therapy. Semin Hematol. 2003;40 Suppl 3:3-9.

34. Manco-Johnson MJ, Abshire TC, Shapiro AD, et al. Prophylaxis versus episodic treatment to prevent joint disease in boys with severe hemophilia. N Engl J Med. 2007;357(6):535-544. 
35. Astermark J, Petrini P, Tengborn L, Schulman S, Ljung R, Berntorp E. Primary prophylaxis in severe haemophilia should be started at an early age but can be individualized. Br J Haematol. 1999; 105(4):1109-1113.

36. Fischer K, van der Bom JG, Molho P, et al. Prophylactic versus ondemand treatment strategies for severe haemophilia: a comparison of costs and long-term outcome. Haemophilia. 2002;8(6):745-752.

37. du Treil S, Rice J, Leissinger CA. Quantifying adherence to treatment and its relationship to quality of life in a well-characterized haemophilia population. Haemophilia. 2007;13(5):493-501.

38. Jimenez-Yuste V, Alvarez MT, Martin-Salces M, et al. Prophylaxis in 10 patients with severe haemophilia $A$ and inhibitor: different approaches for different clinical situations. Haemophilia. 2009;15(1):203-209.

39. Lippert B, Berger K, Berntorp E, et al. Cost effectiveness of haemophilia treatment: a cross-national assessment. 2005;16(7):477-485.

40. Carlsson KS, Hojgard S, Lindgren A, et al. Costs of on-demand and prophylactic treatment for severe haemophilia in Norway and Sweden. Haemophilia. 2004;10(5):515-526.

41. Colowick AB, Bohn RL, Avorn J, Ewenstein BM. Immune tolerance induction in hemophilia patients with inhibitors: costly can be cheaper. Blood. 2000;96(5):1698-1702.

42. Morfini M, Haya S, Tagariello G, et al. European study on orthopaedic status of haemophilia patients with inhibitors. Haemophilia. 2007;13(5): 606-612.

43. Silva M, Luck JV Jr, Siegel ME. 32P chromic phosphate radiosynovectomy for chronic haemophilic synovitis. Haemophilia. 2001;7 Suppl 2: 40-49.

44. Ballal RD, Botteman MF, Foley I, Stephens JM, Wilke CT, Joshi AV. Economic evaluation of major knee surgery with recombinant activated factor VII in hemophilia patients with high titer inhibitors and advanced knee arthropathy: exploratory results via literature-based modeling. Curr Med Res Opin. 2008;24(3):753-768.

45. Rodriguez-Merchan EC, Rocino A, Ewenstein B, et al. Consensus perspectives on surgery in haemophilia patients with inhibitors: summary statement. Haemophilia. 2004;10 Suppl 2:50-52.

46. Hoots WK, Ebbesen LS, Konkle BA, et al. Secondary prophylaxis with recombinant activated factor VII improves health-related quality of life of haemophilia patients with inhibitors. Haemophilia. 2008;14(3): 466-475.

47. Hay CR. Prophylaxis in adults with haemophilia. Haemophilia. 2007; 13 Suppl 2:10-15.

48. Tagliaferri A, Franchini M, Coppola A, et al. Effects of secondary prophylaxis started in adolescent and adult haemophiliacs. Haemophilia. 2008;14(5):945-951.

49. Royal S, Schramm W, Berntorp E, et al. Quality-of-life differences between prophylactic and on-demand factor replacement therapy in European haemophilia patients. Haemophilia. 2002;8(1): 44-50.

50. Green C, de Cock E. Cost-consequences of orthopaedic surgery in haemophilia patients with inhibitors. International Society for Pharmacoeconomics and Outcomes Research Fourth Annual European Congress; November 11-13, 2001; Cannes, France.
51. Health Resources and Services Administration, US Department of Health and Human Services. Find a health center. Available from: http:// findahealthcenter.hrsa.gov. Accessed April 22, 2013.

52. Centers for Medicare and Medicaid Services (CMS), US Department of Health and Human Services. Children's health insurance program. Available from: http://www.medicaid.gov/CHIP/CHIP-Program-Information. html. Accessed April 24, 2013.

53. Teitel JM, Barnard D, Israels S, Lillicrap D, Poon MC, Sek J. Home management of haemophilia. Haemophilia. 2004;10(2):118-133.

54. Van Dijk K, Van Der Bom JG, Bax KMA, Van Der Zee DC, Van Den Berg HM. Use of implantable venous access devices in children with severe hemophilia: benefits and burden. Haematologica. 2004;89(2): 189-194.

55. Ljung R. Central venous catheters in children with haemophilia. Blood Rev. 2004;18(2):93-100.

56. Ljung R, van den Berg M, Petrini P, et al. Port-a-Cath usage in children with haemophilia: experience of 53 cases. Acta Paediatr. 1998;87(10): 1051-1054.

57. De Moerloose P, Urbancik W, Van Den Berg HM, Richards M. A survey of adherence to haemophilia therapy in six European countries: results and recommendations. Haemophilia. 2008;14(5):931-938.

58. Petrini P, Seuser A. Haemophilia care in adolescents: compliance and lifestyle issues. Haemophilia. 2009;15 Suppl 1:15-19.

59. Fischer K. Can we consider discontinuing primary prophylaxis in adults with severe haemophilia? Haemophilia. 2008;14 Suppl 4:10.

60. Richards M, Altisent C, Batorova A, et al. Should prophylaxis be used in adolescent and adult patients with severe haemophilia? An European survey of practice and outcome data. Haemophilia. 2007;13(5): 473-479.

61. Seuser A, Boehm P, Kurme A, Schumpe G, Kurnik K. Orthopaedic issues in sports for persons with haemophilia. Haemophilia. 2007; 13 Suppl 2:47-52.

62. DiMichele D, Neufeld EJ. Hemophilia. A new approach to an old disease. Hematol Oncol Clin North Am. 1998;12(6):1315-1344.

63. Inalex Productions. A Bright Future. A DVD Series for People Living with Hemophilia. Available at: http://inalexus3r.hostcentric. com/InalexProductions/InalexProductions.htm. Accessed November 9, 2009.

64. Deutsch JE, Borbely M, Filler J, Huhn K, Guarrera-Bowlby P. Use of a low-cost, commercially available gaming console (Wii) for rehabilitation of an adolescent with cerebral palsy. Phys Ther. 2008;88(10):1196-1207.

65. Phillips JM. Childhood obesity and hemophilia. In: Bloodline: A Newsletter Designed for Members of the Bleeding Disorders Community. Cincinnati, OH: Cincinnati Children's Hospital Medical Center. 2006;(1):4-5.

66. Vandewater EA, Shim MS, Caplovitz AG. Linking obesity and activity level with children's television and video game use. J Adolesc. 2004;27(1):71-85.

67. National Hemophilia Foundation. Camp directory. Available from: http://www.hemophilia.org/NHFWeb/MainPgs/MainNHF. aspx?menuid=258\&contentid=559. Accessed April 29, 2013.
Journal of Blood Medicine

\section{Publish your work in this journal}

The Journal of Blood Medicine is an international, peer-reviewed, open access, online journal publishing laboratory, experimental and clinical aspects of all topics pertaining to blood based medicine including but not limited to: Transfusion Medicine; Blood collection, Donor issues, Transmittable diseases, and Blood banking logistics; Immunohematology; Artificial and alternative

\section{Dovepress}

blood based therapeutics; Hematology; Biotechnology/nanotechnology of blood related medicine; Legal aspects of blood medicine; Historical perspectives. The manuscript management system is completely online and includes a very quick and fair peer-review system. Visit http://www.dovepress.com/ testimonials.php to read real quotes from published authors. 